\title{
Incorporação de discursos no processo participativo de planejamento da cidade: um olhar sobre a elaboração do Plano Diretor do Município de Santana-AP
}

Alexandre Gomes Galindo ${ }^{1}$

1 Doutorando em Sociologia pela Universidade Federal do Ceará, Mestre em Administração pela Universidade Estadual do Ceará. Professor da Universidade Federal do Amapá e Pesquisador Líder do Núcleo de Estratégia, Gestão e Estudos Organizacionais (NEGEO/UNIFAP), Brasil. E-mail: alexandregalindo@bol.com.br

RESUMO: Este artigo apresenta uma análise sobre a dinâmica de construção participativa da cidade baseada nas relações entre as dimensões discursivas envolvidas nos processos de planejamento no Estado do Amapá, em especial, na elaboração do Plano Diretor do Município de Santana realizado nos anos de 2005 e 2006. O presente estudo se ancorou na perspectiva metodológica da observação participante focalizada no olhar sobre a intensidade de envolvimento entre agentes sociais que integraram os diversos loci de referência e de construção discursiva durante as várias etapas deste projeto. Ao mesmo tempo em que houve significativas incorporações, houve também significativas desconsiderações de anseios e manifestações expressas durante os eventos e ações promovidas pelo governo municipal, denotando a existência do risco de várias questões, que foram consideradas por diversos atores sociais como críticas para o desenvolvimento local, se tornarem invisíveis no transcorrer da gestão pública do município. $O$ estudo aponta para o fato de que simples estabelecimento de diálogos com atores sociais como estratégia de participação no desenvolvimento de políticas apresenta limites, sendo necessário o estabelecimento de vias alternativas que garantam, nos processos de planejamento e gestão da cidade, a integridade, o reconhecimento e a incorporação dos discursos legítimos que surgem durante estes diálogos.

Palavras-chave: Participação Social. Planejamento Urbano. Sociologia Urbana. Plano Diretor.

The incorporation of speeches in the process of planning of the city: a look on the Master Plan participatory in the Municipality of Santana - AP

ABSTRACT: This paper realise a analysis on the dynamics of participatory construction of the city based in the relations between the dimensions the discursive wrapped in the processes of planning In the State of the Amapá, especially, in the preparation of the Master Plan of the Municipality of Santana realised the years of 2005 and 2006. The present study anchored in the methodological perspective of the observation participant focused in the look on the intensity of implication between social agents that integrated the diverse loci of reference and of construction discursive during the varied stages of this project. Also it can be registered that to the time that there was significant incorporations, there was also significant slights of 
longings and demonstrations express during the event and actions promoted by the municipal government, denoting the existence of the risk of several questions that were considered by diverse social actors like criticisms for the local development, if they did invisible in the pass of the public gestion of the municipality. The study aims for the fact that the simple establishment of dialogues with social actors like strategy of participation in the development of politics presents limits, being necessary the establishment of alternative roads that guarantee, in the processes of planning and gestion of the city, the integrity, the recognition and the incorporation of the legitimate speeches that arise during these dialogues.

Keywords: Social Participation. Urban Planning. Urban Sociology. Master Plan.

\section{CONSIDERAÇÕES INICIAIS}

O estabelecimento de marcos regulatórios, que exigem o envolvimento social no encaminhamento dos projetos na área da gestão pública, mesmo sendo considerado um avanço, traz em si desafios no que diz respeito à forma como as experiências participativas são realizadas nos mais diversos níveis, áreas setoriais ou etapas de desenvolvimento das políticas públicas. Neste sentido, a incorporação dos anseios, discursos, demandas e proposituras daqueles que ocupam a cidade nas dinâmicas da gestão, é um exemplo de desafio que deve tanto ser analisado por pesquisadores, quanto enfrentado por aqueles que atuam como representantes do aparelho de Estado.

Este breve ensaio navega sobre a dinâmica de construção participativa da cidade baseada nas relações entre as dimensões discursivas envolvidas nos processos de planejamento no Estado do Amapá, em especial, na elaboração do Plano Diretor do Município de Santana realizado nos anos de 2005 e 2006. Sobre esta ótica, o trabalho gravita através de inquietações associadas a algumas questões norteadoras, tais como: De onde surgiram os discursos incorporados no processo de elaboração do Plano Diretor do Município de Santana? Quais atores ocuparam os loci de referência e de construção discursiva em cada etapa deste processo? Em que grau as arenas de diálogo, utilizadas como meio de compreensão e mediação de significados, foram efetivas ou decorativas? Até onde os "diálogos" e "monólogos" se distinguem? Em que medida há diluições discursivas entre as "primeiras palavras ditas" e as "últimas palavras ditas" no processo de elaboração do Plano Diretor? Desta forma, o presente estudo tem o objetivo de tecer o olhar sobre a implementação do projeto de elaboração participativa do Plano Diretor do Município de SantanaAmapá/Brasil nos anos de 2005 e 2006, descortinando afastamentos e aproximações entre processos de elaboração dos discursos de referência e de construção do referido Plano.

Vale destacar, que as reflexões que se apresentam neste trabalho têm como referência principal a análise sobre a natureza dos discursos na produção do espaço urbano, na medida em que os mesmos são carregados de pressupostos incorporados implicitamente nas palavras e expressões utilizadas pelos diversos grupos e indivíduos. Este esforço de pesquisa se ancorou na perspectiva metodológica da observação 
participante focalizada no olhar sobre a intensidade de envolvimento entre agentes sociais que integraram os diversos loci de referência e de construção discursiva durante as várias etapas deste projeto.

Primeiramente, perpassaremos por uma imersão envolvendo as reflexões teóricometodológicas de Souza (2011) sobre a relação entre discursos e práticas nas delimitações e usos da cidade. Logo após serão apresentados os processos envolvidos na execução do projeto de elaboração participativa do Plano Diretor do Município de Santana, Estado do Amapá, que culminou na promulgação da Lei Municipal Complementar 002/2006. Por fim, serão levantados elementos que apontam para um processo de diluição do discurso dos sujeitos que ocupam espaços e integram as dinâmicas da cidade em detrimento dos discursos daqueles que implementaram a execução do projeto participativo e formalizaram a elaboração do planejamento na estrutura administrativa do poder público.

\section{A CIDADE, A PALAVRA E O PODER NA IMPLEMENTAÇÃO DE PROJETOS DE PLANE- JAMENTO E GESTÃO URBANA: um convite teórico-metodológico de Marcelo Lopes de Souza sobre práticas, imaginários e discur- sos heterônomos e autônomos na produ- ção do espaço urbano}

Marcelo Lopes de Souza é Doutor, docente da Universidade Federal do Rio de Janeiro, e atua como pesquisador que desenvolve estudos vinculados às cidades brasileiras sobre a perspectiva do desenvolvimento sócio-espacial, da teoria urbana e do planejamento urbano, bem como reflexões sobre movimentos sociais, participação popular e espaço. Dentre os vários trabalhos publicados, destacamos sua contribuição no Livro "A Produção do Espaço Urbano: agentes e processos, escalas e desafios" (CARLOS; SOUZA; SPOLITO, 2011) como apoio para análise dos processos participativos de planejamento urbano no Amapá, especificamente da execução do projeto de elaboração do Plano Diretor do Município de Santana, realizada durante os anos de 2005 e 2006.

A escolha deste texto se justifica por sua intencionalidade explícita em servir de elemento provocador para novas abordagens investigativas sobre as cidades, tanto no que se refere à perspectiva teórica, quanto metodológica, na medida em que se propõem penetrar nos significados sociopolíticos dos termos e expressões usadas pelos vários agentes envolvidos nos processos de elaboração e implantação dos projetos participativos de planejamento urbano. No intuito de superar a abordagem estadocentrista na pesquisa sobre planejamento, o autor afirma categoricamente que:

O presente texto é, no estilo e no conteúdo, uma mistura de ensaio com agenda de pesquisas. [...] Concomitantemente, com ele anuncio a minha intenção de me dedicar, sistematicamente, a um tipo de investigação que há muito tempo aprecio e reputo como necessário, embora a isso não me tenha devotado até agora de modo sistemático: consiste no estudo de representações sócio-espaciais com a ajuda da análise de discurso. Além do mais, como em toda agenda de pesquisas, no fundo, trata-se de, explicitamente, convidar outros para que compartilhem comigo esse interesse e essa jornada. (SOUZA, 2011, p. 150). 
Evitando encerrar longa e profunda discussão sobre as abordagens teóricas relacionadas com o conceito de poder, o texto inicia alertando que, ao fazerem uso das palavras, os indivíduos e grupos exercem poder fundamentado em significados sociopolíticos diferentes, e até antagônicos, dos diversos termos usados no quotidiano e que, muitas das vezes, são considerados como técnicos, sendo utilizados como ferramentas neutras de planejamento. Entretanto, na medida em que "a neutralidade axiológica nas ciências sociais é uma pretensão impossível ou absurda, jamais se pensa em tomar as palavras por ferramentas neutras" (SOUZA, 2011, p. 147).

Desta forma, a reflexão mais profunda sobre o uso das palavras utilizadas pelos discursos envolvidos nas intervenções vinculadas ao espaço na cidade, é apresentada como opção factível para superar a predominância do tradicional e limitante enfoque da "visão de sobrevoo" utilizada pelos especialistas que normalmente integram a perspectiva típica do aparelho de Estado nos processos de planejamento "sem adrentar as suas casas, sem mergulhar em seu quotidiano, sem sentir os odores da pobreza, sem ouvir os sons do desespero ou os gritos de libertação" (SOUZA, 2011, p.148).

Esta abordagem busca destacar os produtores efetivos do espaço como elementos ativos que devem ser também considerados em seus discursos e nos significados de suas palavras. O desafio que se aponta diz respeito à dificuldade dos planejadores profissionais agirem como se não tomassem conhecimento do fato de que, além da organização espacial, as relações e práticas sociais exigem que se leve em conta com "muito mais profundidade os homens e mulheres concretos, suas expectativas, seus valores, seus temores. E, claro, suas palavras" (SOUZA, 2011, p. 149). Nesse sentido, o diálogo efetivo (não apenas decorativo) entre os diversos atores sociais, incluindo o próprio Estado, surge como fator imprescindível para superar invisibilidades existentes frente a uma abordagem de planejamento que se apresenta como predominantemente estadocentrista.

Sobre este aspecto, vale destacar que na perspectiva apresentada no texto, longe de ignorar suas prerrogativas legais e privilégios que dispõem, o Estado é entendido como instancia crucial dos processos de elaboração e execução dos projetos de planejamento e de gestão das cidades, e os movimentos sociais vistos, não só como capazes de reagir através de denúncia e protesto, mas também, capazes de agir proativamente, concebendo projetos alternativos/contraprojetos e contraplanos (SOUZA, 2011, p. 149-150). De fato, os sujeitos que integram os focos de estudo em Ciências Sociais Aplicadas, diferentemente do "objeto" das ciências naturais, é ativo e crítico, mudando e fazendo mudar constantemente a realidade, independentemente do observador. É por isso que:

As denominações propostas pelos planejadores estatais, expressão de um saber acadêmico geralmente acrítico e diretamente a serviço da administração dos espaços, tempos e relações sociais, muitas vezes atrita com denominações utilizadas pelos próprios sujeitos que habitam e utilizam os espaços que são alvo das intervenções do Estado, denominações essas embebidas em saberes não acadêmicos (senso comum, "saber local") e referentes ao "mundo da vida" dos agentes (SOUZA, 2011, p. 151). Macapá, v. 6, n. 1, p. 63-80, jan./abr. 2016 
Outro ponto levantado, diz respeito ao fato de que o planejamento urbano profissional na contemporaneidade não se tem limitado apenas a "visões de sobrevoo", havendo também incorporado, desde os anos 1990, esforços teóricos/metodológicos ancorados na preocupação com a análise de discurso e mecanismos de comunicação entre os atores sociais. E são neste contexto que as noções de planejamento colaborativo ou comunicativo surgem como abordagem participativa de gestão das cidades, redirecionando o entendimento do planejamento como "técnica" para planejamento como "discurso" resultante da mediação entre os diversos grupos de interesse e/ou seus representantes (SOUZA, 2011, p.153). Entretanto, frente à assimetria de poder que impede um agir comunicativo pleno entre um Estado planejador dominante e os diversos outros segmentos da sociedade, verifica-se a existência do predomínio de paradigmas tradicionais ainda presentes nas várias propostas de projetos com metodologias participativas implementadas. De certa maneira,

por conseguinte, alguns elementos ideológicos presentes nas abordagens de planejamento mais convencionais e claramente tecnocráticas não deixam de estar presentes também em uma perspectiva como o "collaborative planning": ausência de questionamento radical do status quo sócio-espacial, "estadocentrismo" (ainda que mitigado) e, de algum modo, a persistência de uma predominância da "visão de sobrevoo" (SOUZA, 2011, p. 154).

Assumindo a dimensão heterônoma do planejamento da cidade (dimensão que se característica pela perpetuação de desi- gualdades e dominações em qualquer uma de suas manifestações), o texto destaca a existência de duas categorias de locais de produção discursiva nos processos de planejamento urbano (os "loci de referência discursiva" e os "loci de construção discursiva"). No que se refere a estes locais produtores de discurso,

ainda que os "loci de referência discursiva" (ou seja, as instituições ou sujeitos coletivos-bem como seus espaços-que se convertem em objeto de conhecimento) do planejamento urbano profissional incluam, como elementos da totalidade sócio-espacial concreta, os oprimidos e seus espaços de vida e trabalho, os "loci de construção discursiva" dos planejadores profissionais (e também da maioria dos estudiosos do urbano em geral), isto é, os ambientes a partir dos quais seus discursos são elaborados, tem sido predominantemente, a administração estatal, as universidades e as firmas privadas de consultoria. [...] Enquanto os "loci de construção discursiva" do planejamento urbano profissional são, via de regra, as instituições do aparelho de Estado e o mercado capitalista, os "loci de referência discursiva" do discurso popular são os próprios "mundos da vida" (SOUZA, 2011, p. 154-155).

Sobre esta perspectiva, tanto o pesquisador, quanto o planejador são remetidos à necessidade de atuarem através de uma postura ética e política coerente, na medida em que o diálogo aberto e próximo dos "mundos da vida" aparece como instrumento mais adequado para evitar o predomínio dos reducionismos oriundos de rigor técnico-acadêmico e do "olhar de sobrevoo", através de uma busca constante para 
compreender os significados impressos pela realidade social, de tal forma que invisibilidades e estigmas sejam adequadamente assumidos e enfrentados (SOUZA, 2011, p. 154-159).

Ao apontar para uma agenda de pesquisas, se destacam as representações sócioespaciais como categoria de análise plausível nos estudos da produção do espaço urbano, na medida em que "são um campo de disputa simbólica, e as 'significações imaginárias sociais' que, tão amiúde, nelas se acham reificadas ou diluídas, são, simultaneamente, também 'armas' simbólicodiscursivas dessas contendas" (SOUZA, 2011, p. 160). Desta forma, o "nanoterritório" (representando a escala das casas, oficinas, ruas, praças, pessoas amontoadas em viadutos, espaços de trabalhos das prostitutas, celas e espaços em presídios, dentre outros) surge como elemento demarcador para o diálogo com os "mundos da vida". Entretanto, tanto o pesquisador, e em extensão o planejador, devem estar atentos sobre o fato de que:

"olhar de longe" não é, necessariamente, algo censurável de um ângulo éticopolítico e, muito menos, científicometodológico. [...] a solução consiste em saber combinar as escalas (refiro-me, aqui, tanto a escalas de análise quanto a escalas de ação), de tal maneira que não se precise, por constrangimento epistemológico ou metodológico, e muito menos por indução ideológica, abdicar de nenhuma delas. [...] É assim, antes integrando que descartando a priori qualquer nível, sabendo combinar o "olhar de perto" (aquele que exige "estar dentro", que implica ser um insider ou qualquer insider) com o "olhar de longe" (aquele que permite e mesmo exige "colocar-se de fo- ra" e à distancia), que o "olhar de longe" não precisará ser visto como uma "visão de sobrevoo" arrogante, verdadeiro antípoda ético-político do "olhar de perto/de dentro (SOUZA, 2011, p. 161).

Ainda sobre a perspectiva metodológica, são sugeridas (SOUZA, 2011, p. 162-163), atividades específicas para pesquisadores interessados no estudo das práticas espaciais em sua ambiência quotidiana, em especial a valorização do trabalho de campo intensivo em nanoterritórios (preferencialmente através de pesquisa participante ou pesquisa-ação); a familiarização crítica do contexto através do estudo das representações sócio-espaciais; discussões teóricas e aplicação de procedimentos de análise de discurso.

Nos aspectos conclusivos do texto, são levantados dois pontos essenciais que também devem ser levados em conta na analise dos processos de planejamento participativo. O primeiro diz respeito à atenção que se deve ter frente aos momentos de construção discursiva do planejamento (na medida em que "'Dizer as últimas palavras' ou 'ter a palavra final' significa em várias línguas, decidir") e o segundo diz respeito à atenção que também se deve ter "para as palavras em si, e não somente para a decisão explícita que encerram", visto que, muito já são elas carregadas de poder, significado e implicações (SOUZA, 2011, p. 163).

As abordagens propostas se apresentam como rotas efetivas de estudo dos fenômenos sociais, resultantes de uma trajetória de reflexões já percorrida pelo autor e vinculada às dinâmicas de elaboração dos projetos de planejamento e uso dos espaços da cidade (SOUZA, 2006; 2007), sugerindo ao pesquisador, ao planejador e aos diversos 
outros atores sociais desenvolverem práticas emancipatórias que incorporem a integração entre discursos acadêmico-científico, técnico com o senso comum.

\section{ASPECTOS METODOLÓGICOS E PARTICI- PAÇÃO SOCIAL DO PROJETO DE ELABORA- ÇÃO DO PLANO DIRETOR DO MUNICÍPIO DE SANTANA, ESTADO DO AMAPÁ}

O Município de Santana (Figura 1), instituído em 1987, localiza-se às margens da Foz do Rio Amazonas, possuindo vocação portuária (inicialmente fomentada para escoamento de produção extrativista mineral) e comercial (na medida em que integra a Área de Livre Comércio de Macapá e Santana - ALCMS) ${ }^{\underline{1}}$, com $28,6 \%$ de seu território destinado a uma zona, de uso ainda incipiente, com o propósito de abrigar o Parque Industrial do Amapá (TOSTES, 2006). Com uma área territorial de $1.579,608 \mathrm{Km}^{2}$, Santana corresponde ao segundo município mais populoso do Amapá, com 108.897 habitantes estimados em 2013, sendo também o município com o segundo maior PIB do Estado (IBGE, 2014).

\footnotetext{
${ }^{1}$ ALCMS- A Lei n.ㅇ 8.387, de 30 de dezembro de 1991, criou a Área de Livre Comércio de Macapá, no Estado do Amapá, conforme estabelece o art. 11. O Decreto n. 0 517, de 8 de maio de 1992, regulamentou o art. 11, da Lei n.o 8.387/1991, estabelecendo as finalidades e a localização da Área de Livre Comércio de Macapá e Santana - ALCMS.
}

Figura 1 - Mapa da Cidade de Santana-AP Figure 1 - Map of Santana-AP City

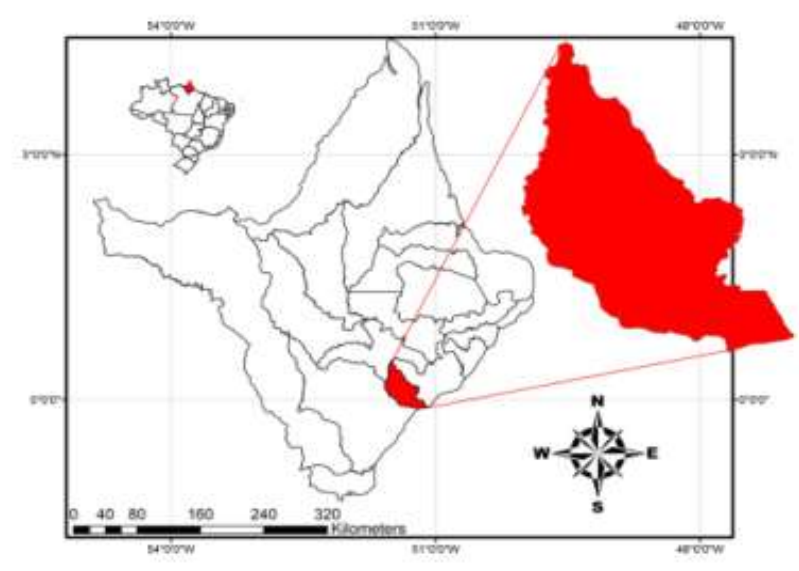

Fonte: Brito (2013).

Desde sua criação, Santana tem incorporado em seu desenvolvimento territorial processos de planejamento urbano promovidos pelo Estado através de mecanismos formais alinhados com os marcos regulatórios direcionadores da política urbana nas cidades brasileiras (BRASIL, 1988; 2001), dentre eles a elaboração de Planos Diretores.

Na qualidade de município, nas décadas de 1990 e 2000, Santana vivenciou dois processos distintos de elaboração de Plano Diretores, sobre a perspectiva da participação. O primeiro, elaborado em parceria com a Superintendência de Desenvolvimento da Amazônia (SUDAM)ํㅡㄹ é aprovado em 1995, sendo

um documento tecnicamente muito bem constituído, tendo um amplo diagnóstico

\footnotetext{
${ }^{2}$ A Superintendência do Desenvolvimento da Amazônia (SUDAM) é uma autarquia do governo federal do Brasil, criada no governo do presidente Castelo Branco em 1966, com a finalidade de promover o desenvolvimento da região amazônica, gerando incentivos fiscais e financeiros especiais para atrair investidores privados, nacionais e internacionais. Ela tem sede e foro em Belém, e é vinculada ao Ministério da Integração Nacional.
} 
do Município de Santana, porém o plano não é colocado em prática porque o mesmo não é do conhecimento da sociedade que não sabe a serventia deste instrumento público (TOSTES, 2006, p. 107).

Entretanto, sobre marcante influência normativa do Estatuto das Cidades (BRASIL, 2001), o projeto de elaboração do Plano Diretor, desenvolvido entre os anos de 2005 e 2006, incorporou forte viés participativo com o propósito de catalisar as contribuições dos diversos atores sociais que integram as dinâmicas locais de uso dos espaços no município. Inclusive, este viés participativo de planejamento permaneceu incorporado na proposta, apresentada em 2011, para sua revisão (GALINDO, 2012).

Não muito diferente do contexto atual, Santana possuía no período da elaboração do Plano Diretor, segundo estudos de $\underline{\mathrm{Ra}}$ mos (2006), uma população predominantemente jovem e urbana, caracterizada pela pobreza e baixa escolaridade, onde e aproximadamente $80 \%$ da população economicamente ativa obinha rendimentos médios mensais de até dois salários mínimos e o setor terciário (comércio e serviços) possuía a maior expressão frente às ocupações desenvolvidas. No que se refere à saúde, saneamento básico e transporte, o referido autor indica também que: 1) a oferta de serviços de saúde para a população era precária (com significativo déficit de leitos e profissionais); 2) aproximadamente $42 \%$ dos domicílios urbanos não eram providos permanentemente de uma rede de abastecimento de água tratada; 3) mais de 95\% dos domicílios existentes na área urbana não possuíam banheiro ligado à rede geral de esgoto; 4) aproximadamente $18 \%$ dos domicílios urbanos e $70 \%$ dos domicílios rurais não eram atendidos pelos serviços de coleta de lixo e 5) o sistema de transporte não atendia com eficiência as demandas dos moradores.

Com a posse de uma nova equipe de governo municipal, e frente à obrigatoriedade constitucional, em 2005 foram tomadas iniciativas para instaurar uma equipe de trabalho composta por técnicos da prefeitura para realizar e gerenciar o processo de elaboração do Plano Diretor (SANTANA, 2005, p. 7-28; 2007, p. 07-16). Este processo foi desenvolvido em um projeto de quatro etapas durante os anos de 2005 e 2006 assim distribuídas: 1a Etapa- criação de uma Gerência de Projetos e de um Grupo inicial de Trabalho para Plano Diretor compostas por técnicos da Prefeitura; 2a $\underline{\text { a }}$ Etapa- mobilização e formação de gestores e técnicos da prefeitura e de lideranças da sociedade civil para participarem do processo; 3a realização de amplo diagnóstico municipal (denominado de Leitura da Cidade) e 4ạ Etapa- Sistematização/elaboração do projeto de Lei do Plano Diretor e sua submissão à Câmara Municipal para avaliação, ajustes e aprovação final (Figura 2).

Figura 2 - Processo de Elaboração do Plano Diretor do Município de Santana

Figure 2 - Preparation process of the Master Plan of the Municipality of Santana

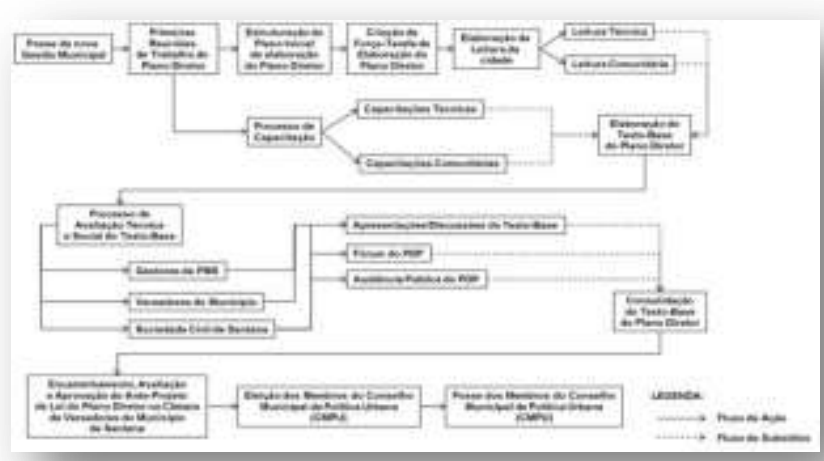

Fonte: Santana (2007). 
A sistemática adotada incorporou o estabelecimento de diversos canais de participação envolvendo momentos de sensibilizações, capacitações, sistematizações, pesquisas, consultas e deliberações nitidamente demarcados e a etapa de diagnóstico municipal englobou um conjunto de estratégias que visaram congregar perspectivas denominadas de "técnicas" e "comunitárias" em um mosaico capaz de servir de referência para "olhares" diversos do município (SANTANA, 2006, p. 07-14).

$\mathrm{Na}$ perspectiva "técnica" (Figura 3 ), os seguintes elementos integraram esta leitura: 1) dados e mapas oriundos do Plano Diretor de Desenvolvimento Integrado do Município-SUDAM (1991-1995); 2) dados e mapas existentes e sistematizados no banco de informações do IBGE ${ }^{3}$; 3 ) dados e mapas existentes e sistematizados pelas Instituições Estaduais de Pesquisa e Meio Ambiente; 4) legislação relacionada com o planejamento urbano do município (Lei Orgânica e Leis Complementares); 5) pesquisa de sondagem realizada entre as Secretarias Municipais da Prefeitura; 6) artigos técnicos publicados sobre pontos críticos do planejamento e da gestão púbica e urbana; 7) Pesquisas de Levantamento de Dados da Gerencia de Projetos da Prefeitura Municipal (Levantamentos Bibliográficos diversos, Coletas de Dados in loco, confecção de mapas, dentre outros) e 8) Catalogação dos registros sobre planejamento e gestão pública geral e de Santana (Registros Históri-

\footnotetext{
${ }^{3}$ O diploma criador do IBGE - Decreto no 24.609/34 situou-o como uma entidade de natureza federativa, destinada a promover e a fazer executar ou orientar tecnicamente todas as estatísticas nacionais, mediante progressiva articulação e cooperação das três órbitas administrativas da organização política da República, obtida por convênios, atribuições que não se enquadravam nos órgãos tradicionais do Governo.
}

cos e fotográficos, documentários técnicos, livros, artigos etc).

Figura 3 - Perspectiva "técnica" da Leitura da cidade Figure 3 - Perspective "technique" of the city of Reading

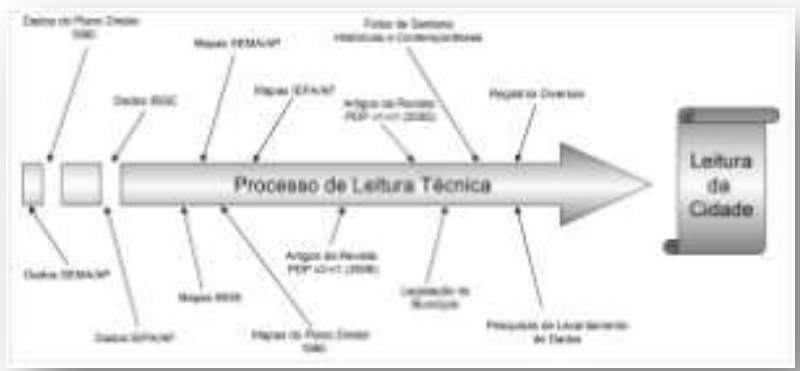

Fonte: Santana (2006).

A perspectiva "comunitária" (Figura 4) englobou as seguintes contribuições sob a ótica das potencialidades, problemas e conflitos, com a pretensão de apresentar elementos do contexto, de tal forma que subsidiassem o aparecimento de diversas interpretações e "olhares" sobre o município: 1) manifestações (perguntas e sugestões) registradas nos debates do I Seminário de Capacitação do PDP, ocorrido entre 25 a 27 de julho de 2005; 2) propostas da Sociedade advindas do Processo de Elaboração do Orçamento Participativo de Santana para o ano de 2006 ; 3) proposições oriundas da 2 a Conferência da Cidade de Santana, realizada em 06 de agosto de 2005; 4) resultado da pesquisa de sondagem nas Regiões Políticas Administrativas de Santana (RPAs), realizada no período de setembro a dezembro de 2005, através de questionários de caráter diagnóstico, sobre vários temas relacionados com a gestão e desenvolvimento do município; 5) resultado de três expedições (Caravana do PDP) para registro do contexto municipal, realizadas em novembro e dezembro de 2005 ; 6) resultado do Festival de vídeo "Curta Santana Num Minuto" realizado em novembro de 2005, com 
a premiação das 18 melhores curtasmetragens amadoras de um minuto, produzidos pelos próprios cidadãos, retratando "olhares" sobre o município; 7) manifestações (perguntas e sugestões) registradas nos debates do III Seminário de Capacitação do PDP, ocorrido em 22 de dezembro de 2005; 8) Obtenção de fotos históricas cedidas pelos moradores do município e 9) relatos/registros sobre a origem, desenvolvimento e gestão do município, obtidos durante encontros entre membros do governo municipal e membros da sociedade.

Figura 4- Perspectiva "comunitária" da Leitura da cidade Frame 4- Perspective "community" of the city of Reading

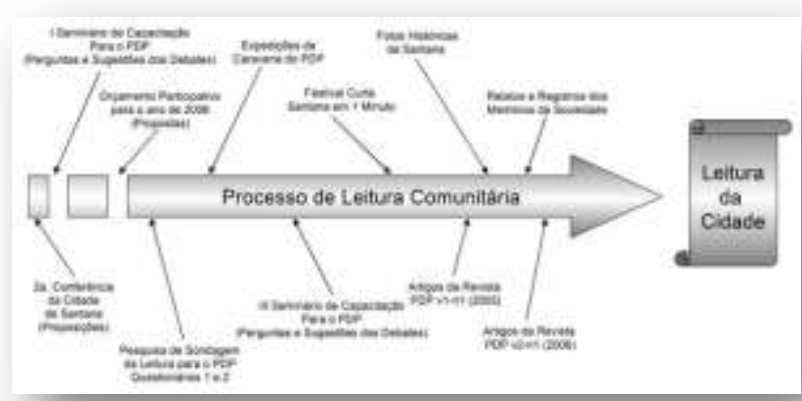

Fonte: Santana (2006)

Durante este período do projeto, houve o envolvimento de servidores municipais, técnicos contratados/voluntários, representantes de instituições públicas estaduais e federais, representantes de órgãos financiadores, instituições públicas e privadas de ensino superior, representantes de diversos setores da sociedade organizadas (associação de moradores, delegados eleitos pelas comunidades, empresas e membros da sociedade interessados em participar das ações) e, por fim, pela Câmara de Vereadores.

O envolvimento destes segmentos, mesmo representando um marco no processo colaborativo do planejamento urbano municipal, se caracterizou por assimetrias de poder influenciadas pela: 1) Condução burocrática e tecnocrática característica do planejamento público; 2) utilização de um novo arcabouço terminológico característico do planejamento urbano que não era dominado por todos os participantes e 3 ) natureza dos encontros entre os diversos stakeholders envolvidos (encontros de sensibilização, consulta, deliberação, sistematização, etc.) que direcionava a concentração de poder para determinados indivíduos e/ou grupos conforme as atividades que eram desenvolvidas em cada momento.

Outrora a existência de nítidas carências reveladas, Freitas (2010) destaca também para o fato de que, mesmo ocorrendo à participação popular com intensidades diferentes ao longo do processo (sendo perceptível a diminuição participativa nas etapas finais do projeto de elaboração do Plano Diretor de Santana), a abertura de canais de diálogo permitiu uma interação significativa entre técnicos, gestores e sociedade civil, possibilitando a incorporação de percepções e demandas locais, hora "invisíveis", no planejamento urbano do município.

\section{OS DISCURSOS DE REFERÊNCIA E DE CONSTRUÇÃO VINCULADOS AO PROJETO DE ELABORAÇÃO DO PLANO DIRETOR DO MUNICÍPIO DE SANTANA: entre "diálogos" e "monólogos"}

No Brasil, após a aprovação do Estatuto da Cidade em 2001, os profissionais e pesquisadores viram-se mais intensamente envolvidos com o fenômeno da participação social nos processos de planejamento e gestão do uso dos espaços urbanos, na medida em que este marco regulatório impunha a obrigatoriedade da abertura de mecanismos de comunicação direta com a socieda- 
de nas metodologias implementadas para elaboração dos planos de gestão. O Município de Santana, no Estado do Amapá, não ficou isento deste fenômeno, sendo visível a incorporação gradual de metodologias participativas nos projetos de construção das peças de planejamento público como, por exemplo, no Plano Diretor Municipal, Plano Municipal de Habitação de Interesse Social, Plano Municipal de Saneamento Básico, dentre outros.

Mesmo havendo incorporações de demandas sociais, antes "invisíveis", na formatação dos planos aprovados pelo poder público (fato esse que já pode ser considerado como avanço operativo), ressalta-se que o estabelecimento de "territorialidades de referência" para a participação popular em vários casos não se tornou plenamente efetivo, em função das assimetrias de poder existentes entre os agentes sociais envolvidos nos diversos momentos de elaboração do planejamento (incluindo as instituições do aparelho de Estado). Desta forma, a intencionalidade e efetividade participativas, institucionalmente divulgadas pelo poder público sobre a construção do Plano Diretor de Santana, por mais que indiquem um marco histórico de mudança paradigmática, nem sempre se apresentaram capazes de representar uma realidade de pleno processo.

O esforço deste estudo em refletir sobre as dinâmicas de planejamento do Município de Santana, baseadas nas relações entre atores envolvidos nos processos participativos desenvolvidos pelo projeto de elaboração do Plano Diretor, se ancorou na perspectiva metodológica da observação participante focalizada no olhar sobre a intensidade de envolvimento entre agentes sociais que integraram os diversos loci de referên- cia e de construção discursiva durante as várias etapas do processo, desenvolvidas nos anos de 2005 e 2006.

O desafio de distanciamento necessário ao atual estudo esteve presente nos procedimentos de análise, na medida em que este olhar partiu de agente integrante da esfera institucional representativa do aparelho de Estado (responsável pela sistematização do planejamento municipal), sendo continuamente enfrentado através de atitudes de estranhamento sobre a efetividade das tentativas de incorporação das demandas sociais durante a realização das estratégias participativas e das sistematizações que formalizaram o processo de elaboração do Plano Diretor.

Nos quadros analíticos gerados pelo presente estudo, a ambiência institucional sistematizadora do Plano Diretor, compreendida como um "contexto vivido" assume escala de nanoterritório, caracterizado, e em grande parte demarcado, pela atuação da Gerência de Projetos da Prefeitura Municipal de Santana como lócus central, dinamizador, indutor e convergente de processos, espaços, diálogos, discursos, conflitos e deliberações, ressalvando-se o papel da Câmara de Vereadores do Município como lócus de deliberação final.

A primeira etapa do projeto de elaboração do Plano Diretor de Santana (caracterizada pela criação da Gerência de Projetos e do Grupo inicial de Trabalho) teve sua ambiência claramente demarcada durante os primeiros seis meses de 2005 através da coordenação exclusiva de instituições do aparelho de Estado, representadas por atores do governo federal (Ministério das $\mathrm{Ci}$ dades e Caixa Econômica Federal) e do governo municipal, que ocuparam respectivamente os loci de referência e de constru- 
ção discursivas neste período.

O alinhamento de discursos institucionais se fez perceber através da associação entre os interesses relacionados com a efetivação de uma política nacional de desenvolvimento urbano (fundamentada no preceito da participação social, proveniente das instâncias federais) e os interesses vinculados com a implantação de uma gestão democrática (declaradamente proposta pela nova equipe de governo municipal) baseada na realização de experiências anteriores vinculadas com abertura de canais de comunicação direta com a sociedade, tendo como exemplo a Emenda Participativa e o Orçamento Participativo.

Entretanto, as arenas de diálogos, que nesta etapa, foram abertas, preenchidas e dinamizadas apenas por atores integrantes do aparelho de Estado, não ficaram isentas de disputas e conflitos, na medida em que a predominância dos elementos regulatórios e direcionadores do governo federal se impuseram como um discurso heterônimo, frente às várias proposituras locais, em especial as relacionadas com financiamento, prazos e alguns procedimentos metodológicos.

Na segunda etapa do projeto de elaboração do Plano Diretor (mobilização e formação de gestores, técnicos e lideranças), ocorreram várias ações com o propósito de agrupar e qualificar o maior número possível de pessoas para atuarem localmente. Nesta etapa, realizada entre julho e dezembro de 2005, a ambiência se caracterizou pela abertura de diversas arenas de diálogo por parte do poder público municipal, com a participação de atores representativos da sociedade civil.

Além de espaço disponibilizado para sociedade nas instalações da Gerência de Pro- jetos (para orientações e estudos contínuos), foram realizados três seminários de capacitação técnica (nos meses de julho e dezembro de 2005); apresentadas palestras sobre o Plano Diretor para 500 delegados do Orçamento Participativo (realizado em agosto de 2005) e realizada uma oficina regional de multiplicadores em Plano Diretor Participativo (em outubro de 2005). Neste contexto, torna-se visível a participação de agentes representativos de segmentos da sociedade local como Universidade Federal do Amapá (UNIFAP), Instituto de Pesquisa do Amapá (IEPA), Instituto Brasileiro de Geografia e Estatística (IBGE/AP), representantes de Associações de Bairros, dentre outros.

Entretanto, da mesma forma que na primeira etapa, a ocupação dos loci de referência e de construção discursiva, se deu predominantemente por atores representativos do poder público (Prefeitura Municipal), com abordagens discursivas heterônomas que apontavam para a consolidação de redes de lideranças locais voltadas para a ampliação da capilaridade de gestão e da condução técnica-metodológica das atividades de elaboração do Plano Diretor conforme as normativas emanadas pelo Estatuto da Cidade.

Na terceira etapa do projeto de elaboração do Plano Diretor (denominada de Diagnose Municipal ou Leitura da Cidade) foram executadas ações voltadas para obtenção de informações da realidade municipal advindas de diversos segmentos da sociedade durante os meses de julho de 2005 a junho de 2006. Diversos atores sociais interagiram através das mais variadas arenas e formas de diálogo, sendo gerado um panorama ampliado da realidade municipal, na medida em que foram descortinados elementos 
que seriam dificilmente identificados pelas abordagens tradicionais de planejamento.

Sobre este aspecto, a experiência santanense, neste período, pode ser considerada como marco de transição entre formas de elaboração do planejamento urbano no município pela incorporação de estratégias institucionais de acolhimento das percepções da realidade local em diversas escalas e formatos, proporcionando aglutinações entre olhares "de longe" e "de perto", permitindo que "visões de sobrevoo" e "olhares" daqueles que integram "os mundos da vida" fossem compartilhados nas ambiências de planejamento e pudessem servir de fundamentação para combinações e/ou mesclagens de perspectivas.

Sete iniciativas de abertura de canais de comunicação com a sociedade se destacaram entre as quinze estratégias utilizadas para realização das leituras "técnica" e "comunitária" de diagnóstico municipal. Uma delas foi à utilização de 22 artigos técnicos e científicos submetidos e publicados em duas Revistas do Plano Diretor, escritos por profissionais de várias áreas (engenharia, arquitetura, administração, sociologia, turismo, educação física, geografia, história, química, geologia e biologia), sobre diversos temas relacionados com o município, como perfil socioeconômico e político municipal; gestão pública e o Plano Diretor; desenvolvimento urbano; patrimônio históricocultural; esporte e lazer; habitação; circulação viária e transporte; saneamento; regulação fundiária; uso e ocupação do solo, dentre outros.

Também foram utilizados os resultados do Io Seminário de Capacitação Interna do Plano Diretor, realizado em julho de 2005, que teve a participação de representantes da prefeitura municipal, Instituto de Pes- quisa do Amapá (IEPA), Instituto Brasileiro de Geografia e Estatística (IBGE), Universidade Federal do Amapá (UNIFAP), Tribunal de Contas da União e de alguns representantes de bairros. Neste Seminário foram transcritos os dezesseis questionamentos feitos para os técnicos envolvidos na condução do processo e oito sugestões advindas dos participantes do evento.

A terceira estratégia utilizada diz respeito ao uso dos resultados advindos das vinte e duas assembleias do processo de elaboração do orçamento municipal participativo, realizadas entre os meses de junho a agosto de 2005 (com o envolvimento de aproximadamente 2.300 pessoas), incluindo o registro das quarenta e cinco proposições de prioridades orçamentárias estabelecidas pelos delegados participantes. A II rência Municipal da Cidade, realizada em agosto de 2005 (com a participação de 102 representantes de vários segmentos sociais), foi utilizada como mais uma estratégia para o diagnóstico da realidade local, incorporando cento e oitenta e duas proposições sobre participação e controle social, questão federativa, política urbana e financiamento para o desenvolvimento urbano, elaboradas pelos participantes nos grupos de trabalho.

Foi realizado também, durante os meses de setembro de 2005 a janeiro de 2006, levantamento (survey) com a aplicação, tabulação e análise de questionários para mil e cinquenta e três munícipes, mapeando quarenta e um conjuntos de demandas locais sobre preservação histórico-cultural, políticas sociais, gestão e gestão compartiIhada, desenvolvimento urbano, circulação viária e transporte, habitação, meio ambiente e distribuição territorial. 
A sexta estratégia de "leitura do município" compreendeu o conjunto de registros gerados pelas oficinas de produção de vídeo amador e da realização do Festival "Curta Santana num minuto" (com a apresentação de 22 vídeos de duração de 1 minuto sobre temáticas relacionadas com o turismo, meio ambiente, história e cultura local), realizadas no período de 05 a 14 de dezembro de 2005, com a participação de 580 pessoas, envolvendo grupos sociais de folclore, esportes radicais, capoeira, hip-hop, dança, terceira idade, alunos de escolas municipais e estaduais, parteiras, profissionais do sexo, catadores de lixo, pescadores, escoteiros, e de outros membros da sociedade.

A sétima abordagem de "leitura" analisada diz respeito ao que foi denominado de Caravanas do Plano Diretor Participativo, representadas por expedições compostas por grupos de técnicos da Gerência de Projetos da Prefeitura que se deslocavam a pé, de bicicleta e/ou de barco para determinadas localidades, com o propósito de observar a realidade local, ter contato com membros da sociedade e registrar as características dos trajetos percorridos e experiências vividas. Foram realizadas três expedições, sendo duas afastadas da região central (realizadas em novembro de 2005) e uma no núcleo urbano do município (realizada em dezembro do mesmo ano). Como resultado, foram identificados e registrados noventa e seis pontos críticos e apontadas vinte e duas sugestões de enfrentamento na busca de proporcionar subsídios, tanto para o processo de elaboração do Plano Diretor, quanto para a elaboração e implantação de políticas públicas específicas nas áreas visitadas.

Ao analisar as experiências de incorporação de "olhares" adotadas no processo de diagnóstico do município, torna-se evidente que nesta etapa ocorre o surgimento de novos atores sociais ocupando os diversos loci de referência discursiva enquanto os agentes representativos da estrutura formal de planejamento público se fazem presentes predominantemente na dimensão das construções discursivas refletidas na maioria dos documentos sistematizados.

Enquanto, em sua maioria, os diversos segmentos da sociedade que se tornaram visíveis nesta etapa denotavam ancorar seus discursos na busca do atendimento de suas microdemandas, os agentes representativos da gestão pública carregavam em seus discursos o pressuposto da importância de ser definido o novo ordenamento territorial de Santana atendendo às pressões de ordem técnica e daquelas oriundas da malha de relação vinculada à governança municipal. Nesta etapa, a ambiência de planejamento se caracterizou pelo surgimento de diversos campos de disputas permeadas pelo ideário de abertura dos canais de diálogo entre a sociedade e o governo municipal.

Um mosaico sobre a realidade local é construído, mesclando "visões de sobrevoo" (observadas nos discursos provenientes dos atores que elaboraram os artigos analisados e do survey aplicado nas regiões político-administrativas do município) com "olhares de perto" (observados nos discursos apresentados pelos atores integrantes das oficinas/festival de curtas metragens e das expedições realizadas pelas Caravanas do Plano Diretor). As assembleias e grupos de trabalho do Orçamento Participativo e da Conferência Municipal da Cidade foram também palcos de grande expressividade dos segmentos sociais e dos confrontos entre as diversas "leituras" da realidade. 
$\mathrm{O}$ descortinamento de demandas sociais tornou visíveis diversas proposições apontando necessidades de construções/reformas de equipamento público, criação de mecanismos formais para participação e controle social contínuos da gestão pública e priorização do uso dos recursos públicos para utilização em saneamento básico, infraestrutura urbana e portuária, habitação e sistema viário.

Por mais que a incorporação das manifestações e proposituras da sociedade no diagnóstico municipal seja considerada um avanço, um ponto importante a ser observado reside no fato de que a equipe técnica da prefeitura exerceu papel ativo em grande parte das "mediações" de conflitos e de interpretações discursivas nas arenas de diálogo, bem como atuou como responsável pela sistematização das "leituras/olhares" produzidas, não ficando, desta forma, este processo totalmente isento de direcionamentos ancorados nos pressupostos vinculados aos interesses daqueles que conduziam o processo.

A quarta e última etapa do projeto de elaboração do Plano Diretor (representada pela sistematização do projeto de lei do plano diretor e sua análise/aprovação pela Câmara de Vereadores) se desenvolveu inicialmente através da elaboração de um texto-base correspondente a versão preliminar do projeto de lei, realizada pelo corpo técnico da prefeitura no período compreendido de janeiro a agosto de 2006. Nos meses de agosto e setembro do mesmo ano, o texto-base foi submetido à apreciação social através da realização de três reuniões abertas de apresentação, um fórum aberto de apresentação e discussão e uma audiência pública de discussão do Plano Diretor. No dia 19 de setembro o Projeto de Lei foi encaminhado à Câmara de Vereadores do município e no dia 05 de outubro de 2006 é aprovada a Lei Complementar 002/2006 que institui oficialmente o novo Plano Diretor sem alterações significativas.

Nesta etapa, as diluições de discursos provenientes dos vários segmentos da sociedade se tornam mais nitidamente expressivas, na medida em que os atores situados nos loci de construção discursiva, responsáveis pela sistematização do planejamento, filtram, definem e redefinem seletivamente as "leituras/olhares" estabelecendo uma versão preliminar das diretrizes gerais da política urbana e rural do município, demarcando genericamente os elementos constitutivos do ordenamento territorial, dos parâmetros para uso, ocupação e parcelamento do solo, dos instrumentos da política urbana e dos mecanismos de gestão democrática da cidade.

Ao tecer a análise do conteúdo apresentado, torna-se evidente a preocupação dos sistematizadores em garantir no corpo do texto a formalização de uma política urbana fundamentada em um Plano Diretor genérico, arremetendo uma significativa parcela de demandas sociais, identificadas na etapa de "Leitura da Cidade", para serem abordadas nos processos futuros de elaboração das Leis complementares como por exemplo, os Planos Municipais de Habitação; de Gestão e Saneamento Ambiental; de Mobilidade Urbana e Rural; de Resíduos Sólidos; de Prevenção do Patrimônio Cultural e as Leis de Parcelamento, uso e ocupação do solo; de Disciplinamento dos Parâmetros para Geradores de Incômodo à Vizinhança; de Obras e Instalações; do Código de Postura, dentre outros.

As apresentações e discussões do plano sistematizado foram caracterizadas nesta 
etapa pelo gradual esvaziamento da participação social e os espaços abertos ao diálogo foram caracterizados por fortes assimetrias de poder, com predominância das influências advindas dos atores representativos do governo municipal. Levando em consideração as diluições de discursos, a diminuição participativa e as assimetrias existentes durante os "diálogos" realizados, pode-se argumentar que na etapa final da construção da peça de planejamento "as últimas palavras ditas" foram permeadas por uma abordagem discursiva tecnocrata e heterônoma, havendo transferências de enfrentamento de demandas locais apontadas pela sociedade para momentos posteriores.

Sobre a perspectiva geral do processo de elaboração do Plano Diretor de Santana, vale a pena registrar que ao mesmo tempo em que houve significativas incorporações, houve também significativas desconsiderações de anseios e manifestações expressas durante os eventos e ações promovidas pelo governo municipal. Este fato (perceptível no confrontamento dos documentos produzidos na etapa diagnóstica com o conteúdo da Lei aprovada pela Câmara de Vereadores), denota a existência do risco de várias questões, que foram consideradas por diversos atores sociais como críticas para o desenvolvimento local, se tornarem "invisíveis" no transcorrer da gestão pública do município.

\section{CONSIDERAÇÕES FINAIS: em busca das "falas daqueles que falaram"}

Ao efetuarmos reflexões sobre o ambiente que envolve os processos de planejamento urbano, estaríamos equivocados se assumíssemos o pressuposto de que a tota- lidade dos discursos, anseios, proposituras e demandas advindas do conjunto de indivíduos que integram determinada sociedade seriam plenamente incorporados nos planos sistematizados ou nas ações realizadas pelo poder público.

Entretanto, o desafio dos estudiosos, dos planejadores e dos gestores do urbano, reside na tentativa de superar as abordagens exclusivamente de "sobrevoo" ao lidarem com as dinâmicas de apropriação e uso dos espaços, em detrimento de um "olhar mais de perto" sobre aqueles "produtores do espaço" que compõe e dão realmente concretude a cada uma destas dinâmicas. Sobre este aspecto, não só o estabelecimento de diálogos com os atores se apresenta como estratégia efetiva de superação. Faz-se necessário também o estabelecimento de vias que garantam o reconhecimento, a incorporação e a integridade dos discursos que se apresentam desde as etapas iniciais do planejamento.

Tomando o exemplo da ambiência na qual convergiram os processos de participação social do projeto de elaboração do Plano Diretor do Município de Santana (onde se tornou perceptíveis diluições de discursos e transferências de enfrentamento de demandas sociais para processos futuros de elaboração de leis complementares), verificam-se pontos de fragilidade na proposta de gestão participativa, na medida em que não se garante que os anseios não contemplados estejam integrados nas arenas futuras de elaboração, implementação, controle e/ou avaliação das políticas públicas no município. Além de diluídas e transferidas, as falas dos "produtores do espaço" se perdem quando não há preocupação ou mecanismos capazes de incorporá-los nas dinâmicas da gestão pública. 
$\mathrm{O}$ avanço alcançado pelo estabelecimento de marcos regulatórios, que exigem o envolvimento social no desenvolvimento da gestão pública, traz em si desafios no que dizem respeito ao modus operandi das experiências participativas propostas para os mais diversos níveis, áreas setoriais ou etapas de desenvolvimento das políticas públicas, sendo a incorporação das falas "dos que ocupam os espaços" nas dinâmicas da gestão um exemplo de desafio que deve tanto ser analisado por pesquisadores, quanto enfrentado por aqueles que atuam como representantes do aparelho de Estado.

Além do trabalho de campo intensivo em nanoterritórios, buscando obter familiarização crítica dos contextos através de discussões teóricas e aplicação de procedimentos de analise de discurso, proposto por Souza (2011), pode-se sugerir também as abordagens de pesquisa voltadas para triangulação criteriosa de métodos e de resultados de análises realizadas em escalas e contextos diferenciados com o propósito de identificar como, quando e de que forma as falas, discursos, anseios e demandas surgentes nos processos participativos são mantidos, diluídos, transferidos e/ou perdidos.

No âmbito da práxis relacionada com a gestão, se destacam como alternativas a abertura de fóruns contínuos de diálogos também em escalas territoriais cada vez menores; o registro histórico criterioso (e de amplo acesso) das falas, discursos, anseios e demandas provenientes de todas as estratégias participativas implementadas; a fusão/integração de conselhos representativos da sociedade que possuem estreitas relações setoriais com o devido suporte estrutural e financeiro para os seus funcionamentos; a implantação dos Sistemas de
Informações Municipais e a implementação de uma filosofia de gestão fundamentada no exercício da descentralização e compartilhamento de poderes com a sociedade, não só na etapa de elaboração do planejamento, mas também nas etapas de implementação, controle e avaliação das políticas públicas.

É na busca e reconhecimento "das falas daqueles que falaram" que, sobre a perspectiva da dimensão discursiva, se pode identificar o verdadeiro esforço de superação das atuais limitações nos processos participativos de gestão, tornando visível uma cidade que se fazia (e também era feita) obscurecida.

\section{REFERÊNCIAS}

BRASIL. Constituição Federal do Brasil. 1998. Disponível em: <http://www.planalto. gov.br/ccivil_03/Constituicao/ConstituicaoC ompilad o.htm>. Acesso em: 22 abr. 2014.

Lei no 10.257, de 10 de julho de 2001. Regulamenta os arts. 182 e 183 da Constituição Federal, estabelece diretrizes gerais da política urbana e dá outras providências. Brasília: Congresso Nacional, 2001. Disponível em: <http://www.planalto.gov.b r/ccivil_03/leis/leis_2001/I10257.htm>. Acesso em: 22 abr. 2014.

BRITO, D. Mapa da Cidade de Santana. Doutorando em Biodiversidade Tropical. Universidade Federal do Amapá, UNIFAP, [Macapá-AP], 2013. Disponível em: <http:// geoabrangencia.blogspot.com.br/2013/10/ proibicao-de-lixoes-desafios-para-2014.htm I>. Acesso em: 22 abr. 2014 .

CARLOS, A. F. A.; SOUZA, M. L. de; SPOLITO, M. E. B. A produção do espaço urbano: agentes e processos, escalas e desafios. São Paulo: Contexto, 2011. 
FREITAS, O. J. B. O princípio da participação popular e a elaboração do Plano Diretor de Santana (AP). PRACS Revista de Humanidades do Curso de Ciências Sociais da UNIFAP, Macapá-AP, n. 3, p. 141-158, dez. 2010.

GALINDO, A. G. Uso da estrutura analítica do projeto (EAP) como ferramenta balizadora na elaboração do projeto de revisão do plano diretor do município de SantanaAmapá-Brasil. In: CONGRESSO AMAPAENSE DE INICIAÇÃO CIENTÍFICA, 3, 2012, Macapá. Livro de Resumos... Macapá: Universidade Federal do Amapá-UNIFAP, 2012. p. 374. INSTITUTO BRASILEIRO DE GEOGRAFIA E ESTATÍSTICA. Cidaes@: informações completas Amapá-Santana-2014. Disponível em: <http://www.cidades.ibge.gov.br/xtras/perf il.php?lang $=\&$ codmun $=160060 \&$ search $=\| \mathrm{i}$ nfogr\%E1ficos:-informa\%E7\%F5es-completa s>. Acesso em: 22 abr. 2014.

RAMOS, J. F. Perfil socioeconômico e político do Município de Santana. Revista do Plano Diretor Participativo, Santana-AP, v. 2, n. 1, p.85-94, jan. 2006.

SANTANA, Prefeitura Municipal. Plano Diretor do Município de Santana: um processo participativo de elaboração. Revista do Plano Diretor Participativo, Santana: PMS, v. 3, n. 1, p. 50, fev. 2007.

. Leitura da Cidade: um olhar para o município de Santana. Revista do Plano Diretor Participativo, Santana: PMS, v. 2, n. 1, p. 218, jan. 2006.

- Ações iniciais de preparação do Plano Diretor Participativo do Município de Santana. Revista do Plano Diretor Participativo, Santana: PMS, v. 1, n. 1, p. 97, jan. 2005.

SOUZA, M. L. de. A cidade, a palavra e o poder: práticas, imaginários e discursos heterônomos e autônomos na produção do espaço urbano. In: CARLOS, A. F. A.; SOUZA, M. L. de; SPOLITO, M. E. B. A produção do espaço urbano: agentes e processos, escalas e desafios. São Paulo: Contexto, 2011. p. 147-166.

A prisão e a Ágora: reflexões em torno da democratização do planejamento e da gestão das cidades. Rio de Janeiro: Bertrand Brasil, 2006.

. Da "diferenciação de áreas" à "diferenciação socioespacial" a "visão (apenas) de sobrevoo" como uma tradição epistemológica e metodológica limitante. Revista Cidades, Presidente Prudente, v.4, n.6, 2007, p. 101-114.

TOSTES, J. A. Planos Diretores no Estado do Amapá: uma contribuição para o desenvolvimento regional. Macapá-AP: Tostes, 2006.

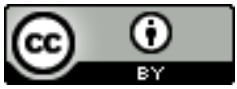

License information: This is an openaccess article distributed under the terms of the Creative Commons Attribution License, which permits unrestricted use, distribution, and reproduction in any medium, provided the original work is properly cited.

Artigo recebido em 24 de outubro de 2015.

Avaliado em 24 de fevereiro de 2016.

Aceito em 07 de março de 2016.

Publicado em 25 de maio de 2016.

\section{Como citar este artigo (ABNT):}

GALINDO, Alexandre Gomes. Incorporação de discursos no processo participativo de planejamento da cidade: um olhar sobre a elaboração do Plano Diretor do Município de Santana-AP. Estação Científica (UNIFAP), Macapá, v. 6, n. 1, p. 63-80, jan./abr. 2016. 